Research Article

\title{
Performance Optimization and Verification of a New Type of Solar Panel for Microsatellites
}

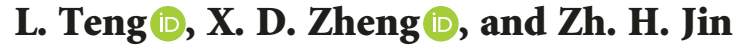 \\ School of Aeronautics and Astronautics, Zhejiang University, Hangzhou 310027, China \\ Correspondence should be addressed to X. D. Zheng; 0015196@zju.edu.cn
}

Received 17 August 2018; Accepted 13 November 2018; Published 27 February 2019

Academic Editor: Christopher J. Damaren

Copyright @ 2019 L. Teng et al. This is an open access article distributed under the Creative Commons Attribution License, which permits unrestricted use, distribution, and reproduction in any medium, provided the original work is properly cited.

\begin{abstract}
In this paper, a new method of replacing the conventional honeycomb aluminum panel with 3D metal printing on the microsatellite is presented. The multiobjective optimization method is used to optimize the temperature difference, compression strength, shear strength, and weight of the new type of solar panel structure. The relationships between the structural parameters and optimization targets are established, and the influence of five factors on thermal and structural properties is analyzed. Finally, a group of better structural parameters of the panel is obtained. The relative deviations between simulation analysis and model are $27.45 \%, 6.12 \%$, $1.365 \%$, and $3.27 \%$, respectively. The optimization results show that the regression model can be used to predict thermal and structural properties of the panel, and the establishment of the model is effective. The analysis results show that the performances can be improved by $91.62 \%, 46.94 \%, 17.91 \%$, and $10.28 \%$, respectively. The optimized results are used for 3D metal printing, and the new type of solar panel is obtained. It is proved that the method can effectively improve the thermal and structural properties of the panel and can effectively shorten the development and manufacture cycle of the panel and also reduce the cost. It has high engineering application value.
\end{abstract}

\section{Introduction}

A solar array is very important in spacecraft because it can convert solar energy into electric power and ensure the continuous operation of spacecraft $[1,2]$. Its main structure is usually made by aluminum honeycomb plates owing to their low density, controllable strength and stiffness, and energy absorption [3-5]. Aluminum honeycomb plates have been widely used in aerospace, train, vehicle, and communication fields $[6,7]$. They are used in the solar array $[2,8,9]$, structural support $[8,10-12]$, and energy dissipation because they can undertake load, absorbing impact kinetic energy, radio waves, and thermal conversions [4, 5, 13-15].

The honeycomb aluminum plate is a sandwich structure that consists of upper and lower layers consisting of thin sheets and a lightweight aluminum honeycomb in the middle. The thin sheets are commonly made of aluminum or composite material $[12,16]$. Owing to its composite structure, a honeycomb aluminum plate has poor thermal conductivity properties when exposed to the sun in space, which can cause a serious temperature change in the solar cell, resulting in heat not being released in time and therefore a decrease in power generation efficiency [17]. Thermal control is crucial in solar panels, and many studies to effectively control their temperature within a permissible range have been conducted. Thornton and Kim [18] and Chung and Thornton [19] studied the thermal response of solar arrays via numerical simulation when the day and night temperature alternated and provided the temperature change results. Ding et al. [20] proposed a method that combined time and temperature fields to analyze the thermal conduction condition of a solar array structure, and the method was proved to be effective for describing thermal nonlinearity. Yang et al. [21] utilized an equivalent conductivity method, which considers all the factors that can cause a temperature change, to calculate the temperature changes of foldable solar arrays; their findings could inform the selection of a suitable launch time. Li et al. [22] established a simplified model method to analyze the temperature change for a rigid solar array when the spacecraft was in a low earth orbit via a numerical simulation, and the result showed that the method could describe the change tendency of the temperature field. Li et al. [23] 
proposed a new thermal model for a composite solar array that was in orbit heat flux, and the analysis results showed that the model could be used to predict the temperature distribution of the whole solar array.

The honeycomb aluminum plate cannot be directly used in the panel or satellite structure, and it is necessary to add inserts in its interior. As the inserts directly determine the mechanical properties of the honeycomb aluminum plate, they are a critical component of the honeycomb aluminum plate [24-31]. When inserts are added to the honeycomb aluminum plate, local stress concentration will increase and cause damage to the structure. This damage usually starts with the debonding of the insert structure from the honeycomb aluminum plate, resulting in breakage of the honeycomb core and destruction of the honeycomb aluminum plate [32]. Therefore, studying and solving the change in the properties of a honeycomb aluminum plate due to the addition of inserts is meaningful for the application of honeycomb aluminum plates.

Burchardt [33] studied the fatigue performance of a sandwich structure with inserts via a fatigue test and simulation, and the results showed that the stiffness of the insert material had no influence on fatigue crack propagation. Demelio et al. [34] investigated the fatigue behavior of a honeycomb structure that was subjected to bending, compression, and shear loads by static and fatigue tests and found that the final failure was due to the compression of the surface layer in the loading area under the action of static load and that the failure was caused by the debonding of the surface layer and the core under the action of the fatigue load. Bozhevolnaya and Lyckegaard [28] proposed a new core insert structure design, whose design parameters were studied with the help of a finite element model. The result showed that the design could greatly reduce the level of damage to the local effect in the face. Cao and Grenestedt [35] evaluated two types of joints under bending and shear loads, and the test results showed that the two types of joints had excellent strength that was close to the strength of the composite sandwich reference sample. Toftegaard and Lystrup [36] developed a finite element parameter method to select a stronger T-joint, and the results, which were verified by simulation and tests, showed that the proposed method could improve the strength and decrease the weight of the T-joint.

The thermal conductivity performance of the honeycomb aluminum plate is poor, and the structure must be pre-embedded to ensure the strength of the installation. The honeycomb aluminum plate is usually purchased from a factory. Generally, it cannot be produced directly by the satellite development unit, which will lengthen the cycle of the plate manufacturing. In addition, the aluminum alloy plate is used directly, or the solar cell is attached to the circuit board as the solar panel on CubeSat $[37,38]$; however, the thermal conductivity and structural strength of the panel are poor, and the weight will be overweight, which will directly affect the life of the solar cell and the power generation efficiency. The thickness of honeycomb aluminum used for solar panels on large satellites is $6-30 \mathrm{~mm}$ [39], with a weight of $4-5 \mathrm{~kg} / \mathrm{m}^{2}$. Furthermore, the cost of the panel is very high and cannot meet requirements as the cost of a microsatellite is several million yuan. Therefore, it is urgent to develop a new type of solar panel. A board structure may be used to solve the highlighted shortcomings of a honeycomb aluminum plate.

In this paper, a new method of replacing the conventional honeycomb aluminum panel with $3 \mathrm{D}$ metal printing on the microsatellite is presented. The multiobjective optimization method is used to optimize the compression strength, shear strength, comprehensive temperature difference, and weight of a new type of solar panel structure. The relationships between the structural parameters of the panel and the optimization targets are established, and the influence of the five factors (the distance between the I-shaped beam and the end of the two layers of aluminum substrate $A$, the width of the I-shaped beam $d$, the thickness of the upper and lower two layers of the aluminum substrate $t$, the number of I-shaped beams $n$, and the thickness of the new type of solar panel $z$, respectively) on temperature difference, compression strength, shear strength, and weight are analyzed. The optimized results are used for 3D metal printing, and a new type of solar panel structure is obtained. It is proved that the presented method can effectively improve the temperature difference, compressive strength, shear strength, and weight reduction of the panel. At the same time, it can effectively shorten the development and manufacture cycle of the panel and also reduce its cost. It has a high engineering application value.

\section{Solar Panel Structure}

2.1. Solar Panel Structure of Internet of Thing (IOT) Satellite. Owing to the tight supply of electricity in an IOT satellite, it is necessary to add a solar array drive assembly (Sada) system to the satellite to track the orientation of the solar panels to the sun. The structures of the satellite and panel are shown in Figure 1. The symmetrical layout of the satellite has two sets of Sada systems with a total of eight solar panels, each of which is $400 \times 375 \mathrm{~mm}^{2}$, and the solar cell with a total area of $1.2 \mathrm{~m}^{2}$, which can guarantee a long-term supply of $170 \mathrm{~W}$ power for the satellite.

If the honeycomb aluminum plate with a thickness of $6 \mathrm{~mm}$ is used, the thermal conductivity performance is poor, as the temperature of the solar cell will rise to $60-80^{\circ} \mathrm{C}$ after the sun's long-term irradiation, and the power generation efficiency will decrease by $30-50 \%$, which will lead to insufficiency of the power generation efficiency of the panel. As a result, the satellite will not function normally. The connection, installation, and fixing of solar panels requires the use of several holes. It is necessary to insert structural parts on the honeycomb aluminum plate. The local stress concentration will affect the structural strength of the panel and will also increase the weight of the plate. The total weight of the panel is estimated as $5 \mathrm{~kg}$. The new type of solar panel achieved with $3 \mathrm{D}$ metal printing can enhance thermal conductivity performance and strength and has a lower weight. The 3D printing method has been used in many fields, as it can effectively improve volume utilization and weight reduction and reduce the cost [38-43]. An analysis of the temperature difference, compressive strength, shear strength, and 


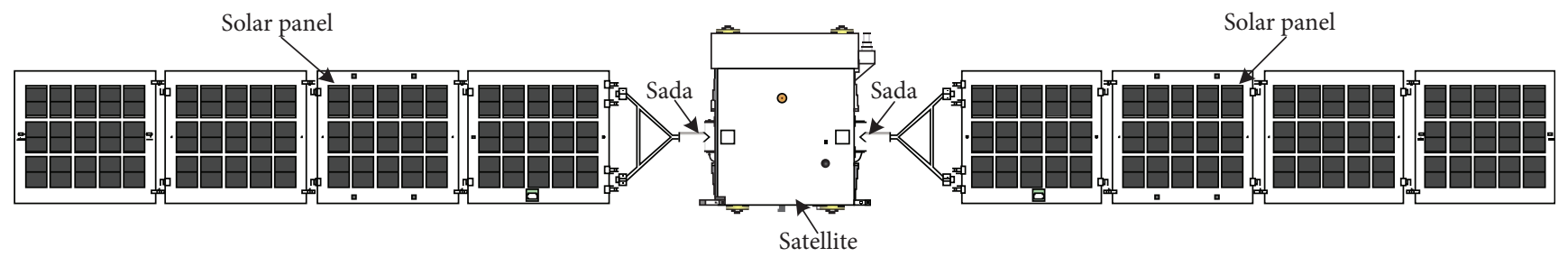

(a)

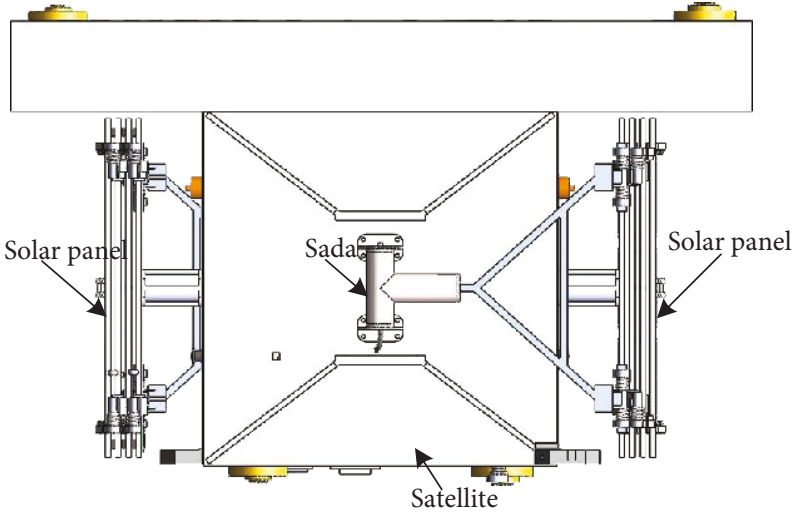

(b)

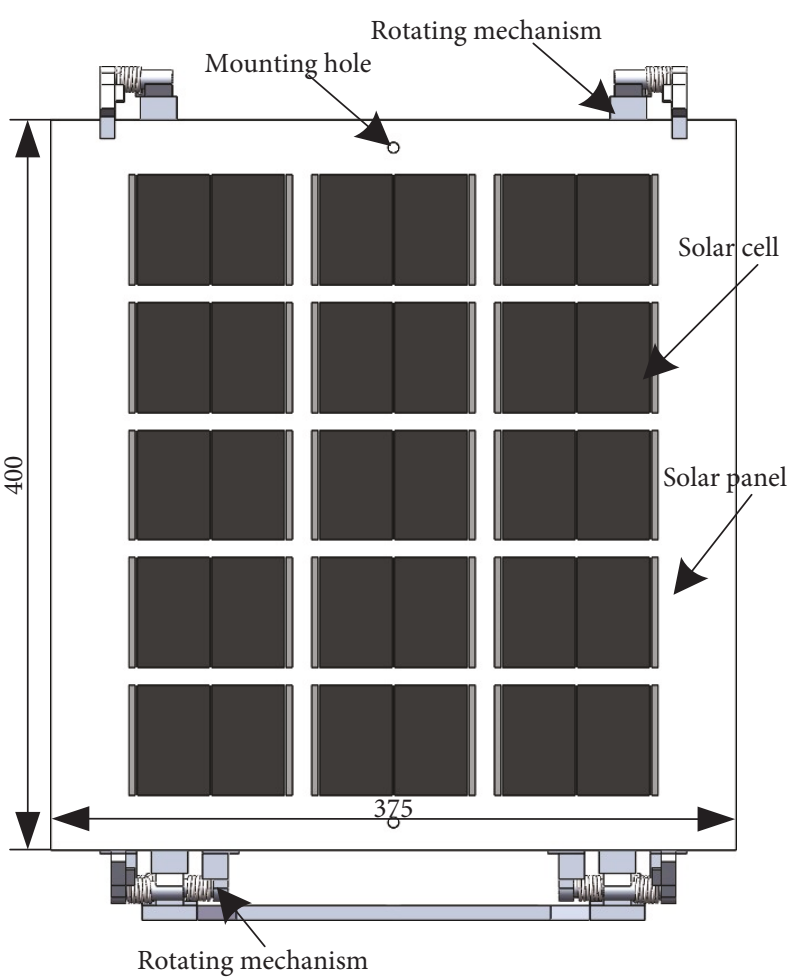

(c)

FIGURE 1: Satellite and solar panel structure: (a) unfolding state, (b) folding state, and (c) solar panel structure.

weight of the $100 \times 100 \times 6 \mathrm{~mm}^{3}$ panel was carried out. The parameters of the new type of solar panel structure were used as optimization factors to optimize the structure.

2.2. The New Type of Solar Panel Structure. According to the analysis in section Solar Panel Structure of Internet of Thing (IOT) Satellite of the honeycomb aluminum plate and the special requirements of the thermal control of the panel, a new I-shaped beam, which is directly connected to the two layers of aluminum substrate, is proposed in this paper. Its basic structure is shown in Figure 2.

The structure of the new type of solar panel structure is mainly determined by seven parameters, and $B$ can be determined by

$$
B=\frac{(x-2 A-n d)}{(n-1)},
$$

where $x=y=100 \mathrm{~mm}, A$ is the distance between the I-shaped beam and the end of the two layers of aluminum substrate, $B$ is the distance between the two I-shaped beams, $d$ is the

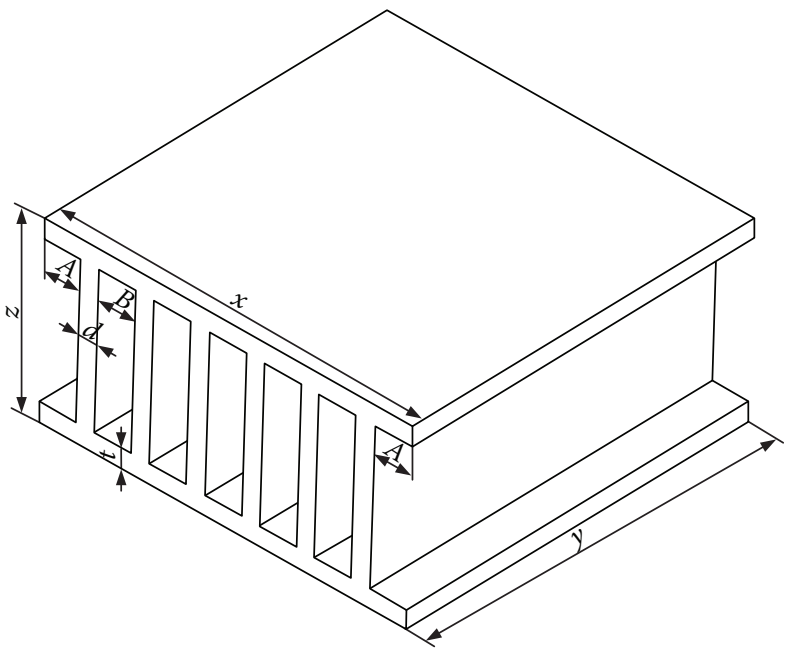

Figure 2: A new type solar panel. 
TABLE 1: Related introduction of selective laser melting (SLM) 3D printing.

\begin{tabular}{lc}
\hline Content & Parameter \\
\hline Material & AA5024 \\
Powder size & $15-53 \mu \mathrm{m}$ \\
SLM equipment & BLT-S310 \\
Temperature & $400-600^{\circ} \mathrm{C}$ \\
Layer height & $0.03 \mathrm{~mm}$ \\
Laser type & $500 \mathrm{~W}$ fiber laser \\
Heat treatment & $280-290^{\circ} \mathrm{C}$, holding time 2 h \\
\hline
\end{tabular}

width of the I-shaped beam, $t$ is the thickness of the upper and lower two layers of the aluminum substrate, and $n$ is the number of I-shaped beams.

According to these parameters, the weight of the new type of solar panel can be determined; it is expressed as

$$
\begin{aligned}
m_{\mathrm{n}} & =\rho_{1}[2 t x y+n d y(z-2 t)] \\
& =\rho_{1}[x y z-2 A y(z-2 t)-(n-1) B y(z-2 t)],
\end{aligned}
$$

where $\rho_{1}$ is the density of aluminum alloy and $z$ is the thickness of the new type of solar panel.

\section{Performance Analysis of the Solar Panel}

3.1. Mechanical Property Measurements. The performance simulation analysis of the panel structure requires the mechanical properties of the $3 \mathrm{D}$ printing material. Therefore, the mechanical properties of the two directions of the $3 \mathrm{D}$ printing material need to be obtained. The related introduction to $3 \mathrm{D}$ printing is shown in Table 1 . The printing process, printing direction, and size of the sample can be found in the literature [43]. The print direction of samples is shown in Figure 3. As the mechanical parameters of the two directions are close, we take their means as the input parameters of the simulation analysis. The material performance parameters in the finite element software are shown in Table 2.

3.2. Performance Analysis of Honeycomb Aluminum Plate. A conventional honeycomb core uses a regular hexagon, and the length of the honeycomb core is $l=2 \mathrm{~mm}$, the thickness of the wall is $(\delta / 2)=0.05 \mathrm{~mm}$ [44], the thickness of the junction of the two units is $\delta$, and the depth is $h=6 \mathrm{~mm}$. In general, the upper and lower plates of a honeycomb aluminum plate are made of a composite material [28], which makes the comprehensive temperature difference of the honeycomb aluminum plates poor. Therefore, the upper and lower two layers of the honeycomb aluminum plate discussed in this paper were also made of a composite material with a thickness of $1 \mathrm{~mm}$ [45] and are shown in Figure 4, where $x, y$, and $z$ are $100 \mathrm{~mm}, 100 \mathrm{~mm}, 6 \mathrm{~mm}$, respectively. The material performance of the core and upper and lower plates are shown in Table 3.

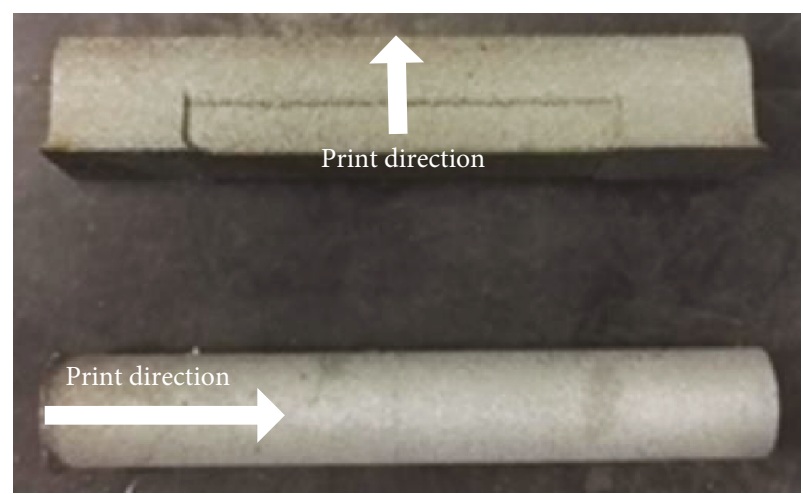

FIgURE 3: The print direction of samples.

According to Figure 4, the weight of the honeycomb aluminum plate can be obtained.

$$
\begin{aligned}
m_{\mathrm{h}}= & \rho_{1}\left\{6(x / 2 \sin \theta)[y /(l+2 \cos \theta)](z-2)\left(\delta+\delta^{2} \operatorname{ctan} \theta\right) t\right\} \\
& +2 \rho_{2} x y(z-5) t,
\end{aligned}
$$

where $\rho_{2}$ is the density of the composite material.

For solar panels, the thermal conductivity performance [9], compression strength [7], shear strength [27], and weight of the panels are important. The temperature difference, compression strength, shear strength, and weight were lower, and the temperature difference, strength, and weight of the structure were better; hence, the performance of the honeycomb aluminum plate should be investigated comprehensively. The model of the honeycomb aluminum plate is shown in Figures 5 and 6, when the on-orbit temperature range of $-70-40^{\circ} \mathrm{C}$, the surface pressure of $10 \mathrm{MPa}$, and the concentrated force of $100 \mathrm{~N}$ are analyzed in the AutoCAD integrated Sinda thermal analysis software and the Abaqus finite element software, respectively. The grid size is $5 \mathrm{~mm}$, and the analysis results are shown in Figure 7 and Table 4.

It can be seen from the analysis results that the temperature difference, compressive strength, shear strength, and weight of the honeycomb aluminum plate are not ideal, especially temperature difference. Because the upper and lower two layers are made out of composite material, which has a poor thermal conductivity, and bonding exists between the composite plate and the honeycomb core, contact thermal resistance will be large. The honeycomb core has a hexagonal shape; moreover, the thickness of the wall is low, and the contact area of the upper and lower upper and lower plates is small. In the presence of direct solar radiation, these features will increase the temperature of the composite plate. As the heat cannot be transmitted to the honeycomb core and radiated out of the plate in time, the temperature difference between the upper and lower two layers of the composite plate will increase, increasing the temperature of the solar cell array, which will affect the generating efficiency of the solar cells.

According to the analysis of the honeycomb aluminum plate, the two layers of composite material on the honeycomb core can enhance the compressive strength and 
TABLE 2: Material properties.

\begin{tabular}{cccccccc}
\hline Material & $\begin{array}{c}\text { Density } \\
\left(\mathrm{kg} / \mathrm{m}^{3}\right)\end{array}$ & $\begin{array}{c}\text { Young's modulus } \\
(\mathrm{GPa})\end{array}$ & $\begin{array}{c}\text { Poisson } \\
\text { ratio }\end{array}$ & $\begin{array}{c}\text { Yield strength } \\
(\mathrm{MPa})\end{array}$ & $\begin{array}{c}\text { Tensile strength } \\
(\mathrm{MPa})\end{array}$ & $\begin{array}{c}\text { Thermal conductivity } \\
(\mathrm{W} / \mathrm{mK})\end{array}$ & $\begin{array}{c}\text { Heat capacity } \\
(\mathrm{J} / \mathrm{kgK})\end{array}$ \\
\hline AA5024 & 2650 & 79 & 0.31 & 450 & 510 & 127 & 845 \\
\hline
\end{tabular}

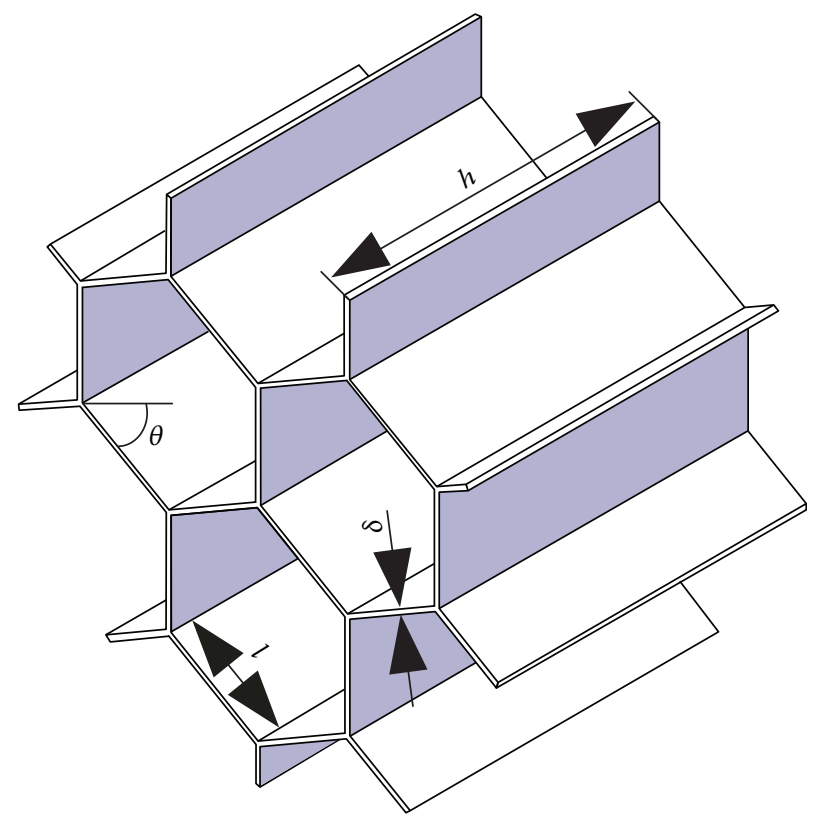

(a)

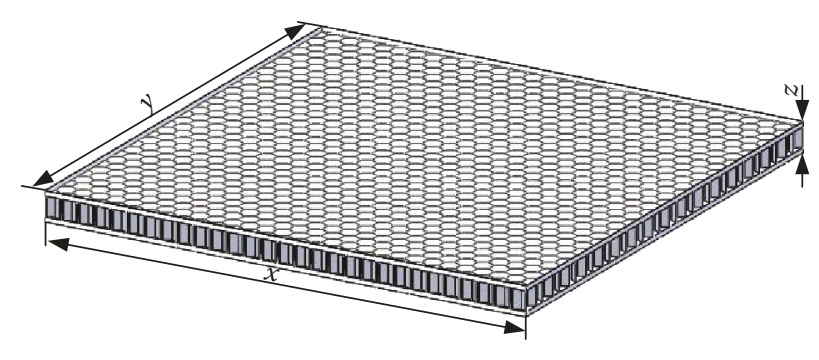

(b)

FIGURE 4: The honeycomb aluminum plate: (a) the size of hexagon honeycomb aluminum and (b) the size of the honeycomb aluminum plate.

TABLe 3: Material properties.

\begin{tabular}{lccccccc}
\hline Material & $\begin{array}{c}\text { Density } \\
\left(\mathrm{kg} / \mathrm{m}^{3}\right)\end{array}$ & $\begin{array}{c}\text { Young's modulus } \\
(\mathrm{GPa})\end{array}$ & $\begin{array}{c}\text { Poisson } \\
\text { ratio }\end{array}$ & $\begin{array}{c}\text { Yield strength } \\
(\mathrm{MPa})\end{array}$ & $\begin{array}{c}\text { Tensile strength } \\
(\mathrm{MPa})\end{array}$ & $\begin{array}{c}\text { Thermal conductivity } \\
(\mathrm{W} / \mathrm{mK})\end{array}$ & $\begin{array}{c}\text { Heat capacity } \\
(\mathrm{J} / \mathrm{kgK})\end{array}$ \\
\hline $\begin{array}{l}\text { Composite } \\
\text { material [4, 7] }\end{array}$ & 1540 & 130 & 0.28 & $/$ & $/$ & 17 & 710 \\
\begin{tabular}{l} 
6061-T6 [46] \\
\hline
\end{tabular} & 2700 & 73.1 & 0.33 & 280 & 300 & 120 & 850 \\
\hline
\end{tabular}

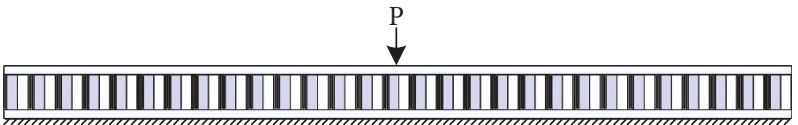

FIgURE 5: Surface pressure $10 \mathrm{MPa}$.

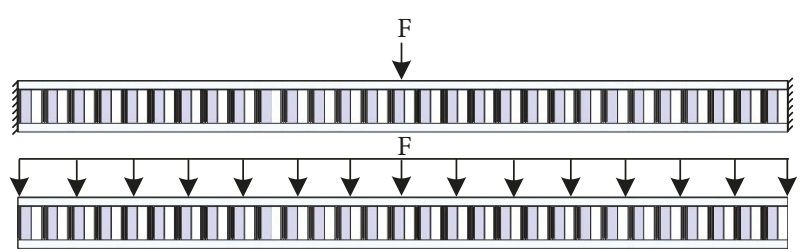

Figure 6: Concentrated force $100 \mathrm{~N}$. shear strength of the plate and reduce its weight; however, the poor thermal conductivity performance of the composite material will result in poor thermal conductivity performance of the honeycomb aluminum plate. If the structure of the composite plate is changed to that of the new type of solar panel structure with aluminum alloy material, the compressive strength, shear strength, and weight reduction will be enhanced while maintaining the structure's thermal conductivity performance.

3.3. Performance Analysis of the New Type of Solar Panel. According to the size of the initial honeycomb aluminum plate, the initial structural parameters of the new type of solar panel are $A=1 \mathrm{~mm}, d=0.5 \mathrm{~mm}, z=6 \mathrm{~mm}, t=0.5 \mathrm{~mm}$, and $n=56$. Then, according to Equations (1) and (2), $B=$ $1.27 \mathrm{~mm}$ and $m_{\mathrm{n}}=67.2 \mathrm{~g}$. The temperature difference, compressive strength, and shear strength of the new type 


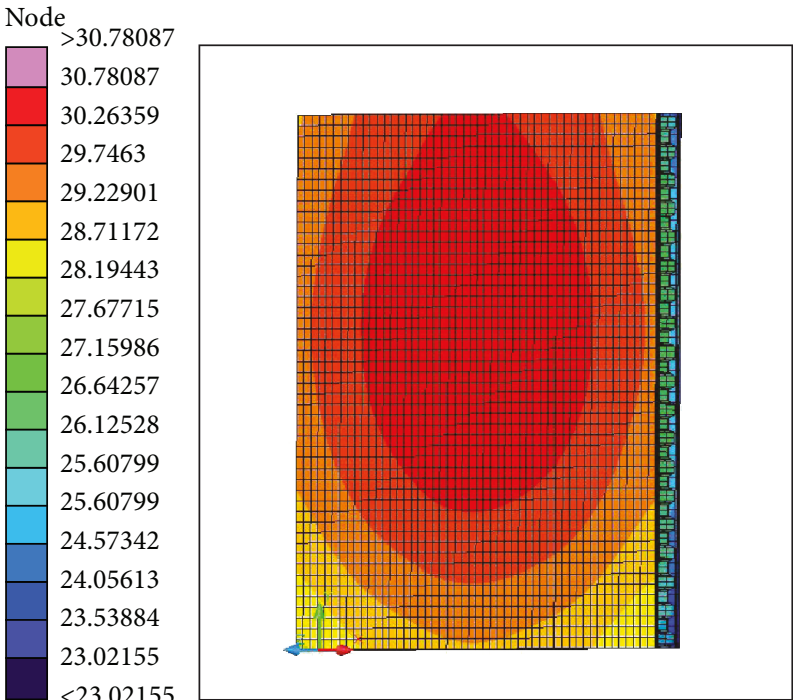

Temperature (C), Time $=0 \mathrm{sec}$

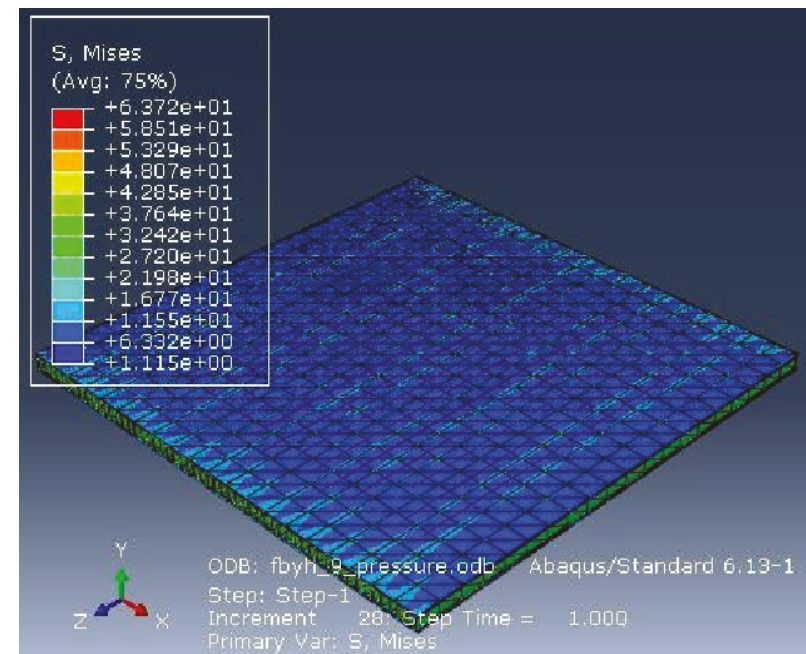

(b)

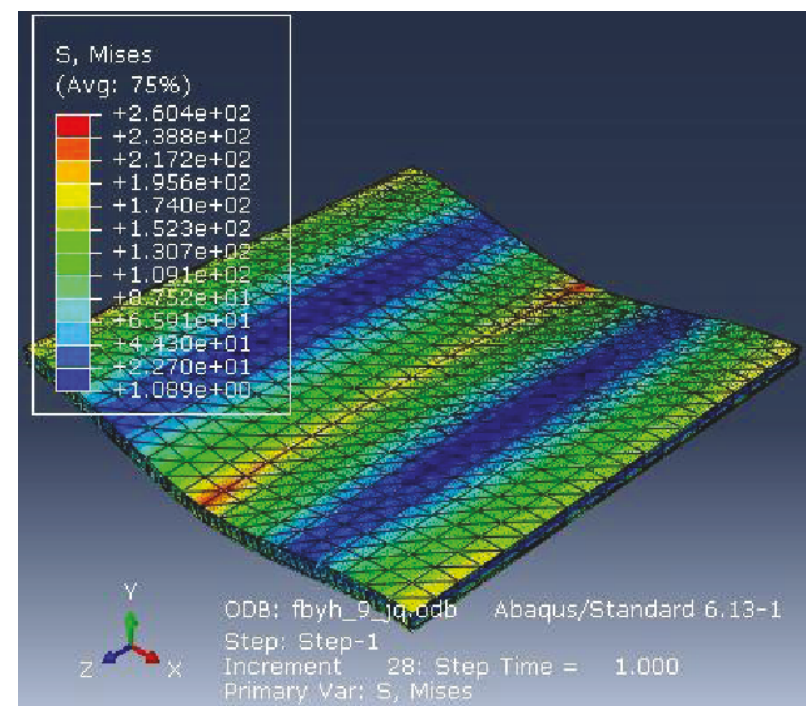

(c)

Figure 7: Performance analysis of honeycomb aluminum plate: (a) temperature difference, (b) compression strength, and (c) shear strength.

TABLE 4: Performance analysis results of the honeycomb aluminum plate.

\begin{tabular}{lccc}
\hline $\begin{array}{l}\text { Temperature } \\
\text { difference }\left({ }^{\circ} \mathrm{C}\right)\end{array}$ & $\begin{array}{c}\text { Compression } \\
\text { strength }(\mathrm{MPa})\end{array}$ & $\begin{array}{c}\text { Shear strength } \\
(\mathrm{MPa})\end{array}$ & $\begin{array}{c}\text { Weight } \\
(\mathrm{g})\end{array}$ \\
\hline 7.76 & 63.72 & 260.4 & 45 \\
\hline
\end{tabular}

of solar panel can be obtained, and they are shown in Figure 8 and Table 5 .

From the initial performance analysis, it can be seen that the temperature difference, compression strength, and shear strength of the new type of solar panel are better than those of the conventional honeycomb aluminum plate, but the weight is $34.4 \%$ higher than that of the conventional honeycomb aluminum plate. To improve the performance of the new type of solar panel, the parameters of the panel structure must be optimized.

\section{Optimization of the New Type of Solar Panel Structure}

4.1. Determination of the Optimization Target. The results of the performance analysis of the third section of the honeycomb aluminum plate and the new type of solar panel indicate that the temperature difference and strength of the panel improve after changing the structure of the panel. If the performance of the new type of solar panel is better than that of the honeycomb aluminum plate, the temperature difference, compression strength, shear strength, and weight have to be adjusted. It can be seen from the analysis results in Tables 4 and 5 that the compressive strength and shear 


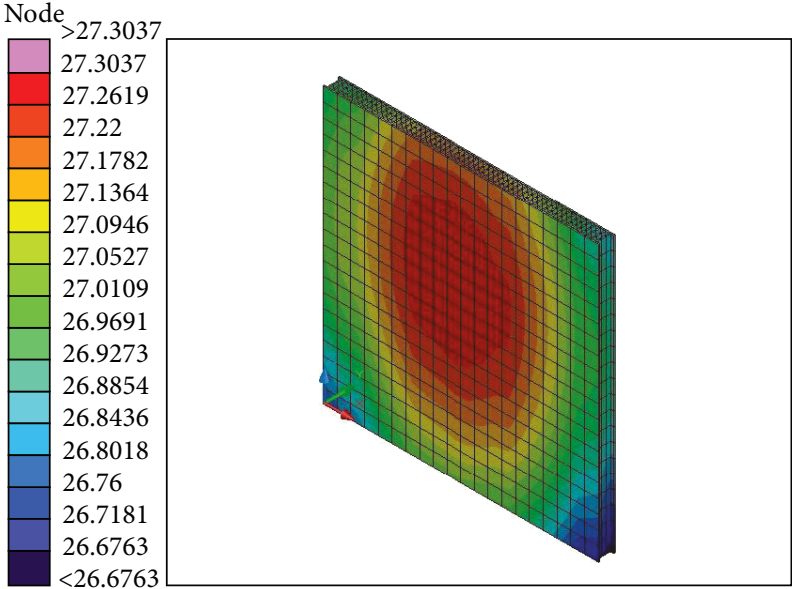

Temperature (C), Time $=0 \mathrm{sec}$

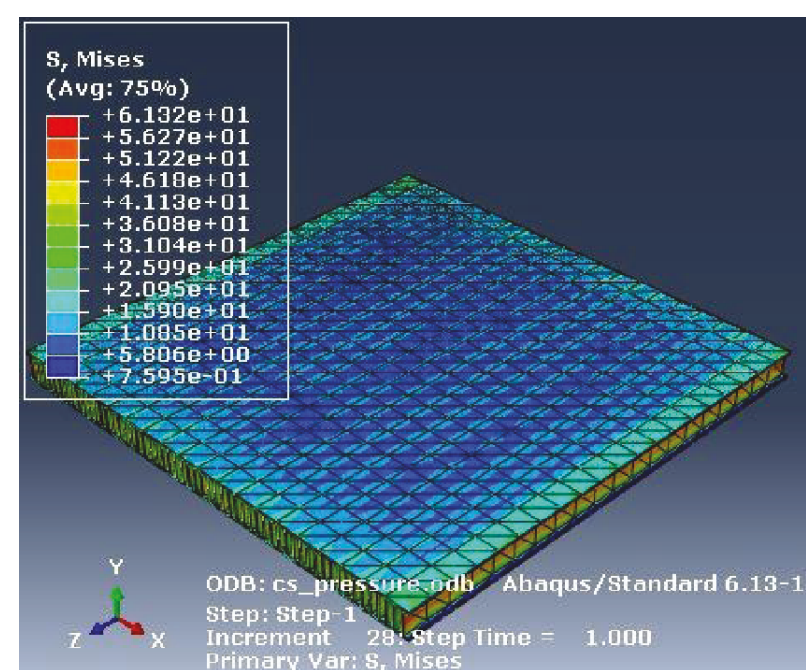

(b)

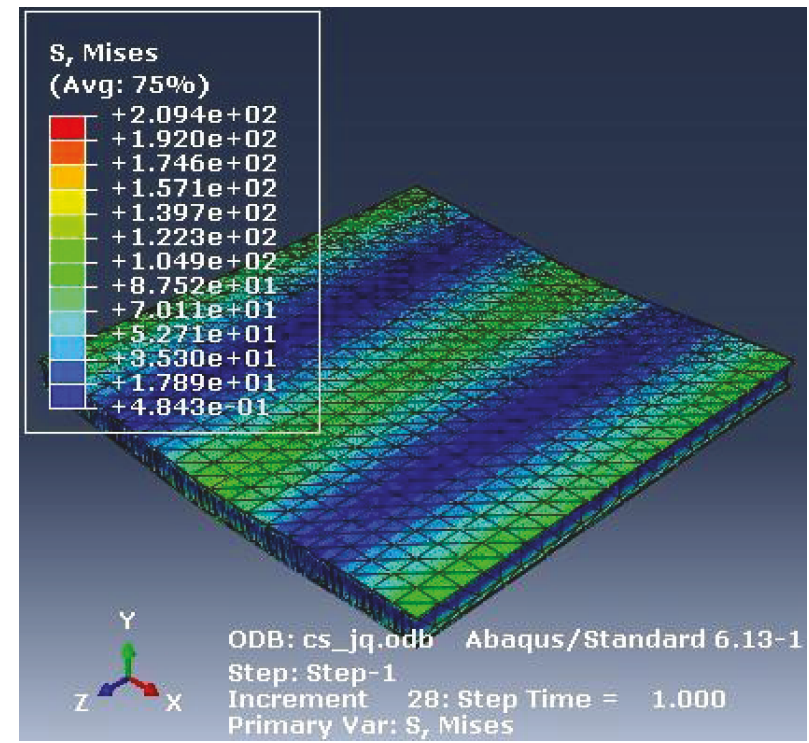

(c)

Figure 8: Performance analysis of the new type solar panel: (a) temperature difference, (b) compression strength, and (c) shear strength.

TABLE 5: Performance analysis results of the new type of solar panel.

\begin{tabular}{lccc}
\hline $\begin{array}{l}\text { Temperature } \\
\text { difference }\left({ }^{\circ} \mathrm{C}\right)\end{array}$ & $\begin{array}{c}\text { Compression } \\
\text { strength }(\mathrm{MPa})\end{array}$ & $\begin{array}{c}\text { Shear strength } \\
(\mathrm{MPa})\end{array}$ & $\begin{array}{c}\text { Weight } \\
(\mathrm{g})\end{array}$ \\
\hline 0.63 & 61.32 & 209.4 & 67.2 \\
\hline
\end{tabular}

strength should be further improved. Because of its structure, the different I-shaped beam's thermal conductivity performance changes only slightly. Because the composite material and honeycomb core are bonded by an adhesive, the weight of the honeycomb aluminum plate should be $50 \mathrm{~g}$, and the new type of solar panel should be improved to some extent compared to the honeycomb aluminum plate. Based on the above analysis, the optimization target of various performance indexes of the new type of solar panel can be seen in Table 6 .
According to the relationship between optimization parameters and optimization targets, the optimization equation can be expressed as

$$
\left\{\begin{array}{c}
T(A, n, d, t, z)=T-0.55=0 \\
\sigma(A, n, d, t, z)=\sigma-30=0 \\
\tau(A, n, d, t, z)=\tau-200=0 \\
m(A, n, d, t, z)=m-46=0 .
\end{array}\right.
$$

4.2. Optimization Process of Panel Performance. For microsatellites, an increase in the volume of the panel leads to an increase in the volume of the satellite. Generally, the solar panel thickness of the microsatellites is $3 \mathrm{~mm}$. Because of the structure of the I-shaped beam, the excess material in 
TABLE 6: Optimization target of the new type of solar panel.

\begin{tabular}{lccc}
\hline Performance & Honeycomb aluminum plate & New type of solar panel & Optimization target \\
\hline$T$ (temperature difference) & $7.76^{\circ} \mathrm{C}$ & $0.63^{\circ} \mathrm{C}$ & $0.55^{\circ} \mathrm{C}$ \\
$\sigma$ (compression stress) & $63.72 \mathrm{MPa}$ & $61.32 \mathrm{MPa}$ & $30 \mathrm{MPa}$ \\
$\tau$ (shear strength) & $260.4 \mathrm{MPa}$ & $209.4 \mathrm{MPa}$ & $200 \mathrm{MPa}$ \\
$m$ (weight) & $50 \mathrm{~g}$ & $67.2 \mathrm{~g}$ & $46 \mathrm{~g}$ \\
\hline
\end{tabular}

TABLE 7: Parameter-level table of the uniform test.

\begin{tabular}{lccccc}
\hline No. & $n$ & $d(\mathrm{~mm})$ & $A(\mathrm{~mm})$ & $z(\mathrm{~mm})$ & $t(\mathrm{~mm})$ \\
\hline 1 & 50 & 0.15 & 0.2 & 3.5 & 0.15 \\
2 & 60 & 0.2 & 0.4 & 4 & 0.2 \\
3 & 70 & 0.25 & 0.6 & 4.5 & 0.25 \\
4 & 80 & 0.3 & 0.8 & 5 & 0.3 \\
5 & 90 & 0.35 & 1 & 5.5 & 0.35 \\
6 & 100 & 0.4 & 1.2 & 6 & 0.4 \\
7 & 110 & 0.45 & 1.4 & 6.5 & 0.45 \\
8 & 120 & 0.5 & 1.6 & 7 & 0.5 \\
\hline
\end{tabular}

TABLE 8: Simulation and calculation results of the uniform test.

\begin{tabular}{lccccccccc}
\hline No. & $n$ & $d$ & $A$ & $z$ & $t$ & $T\left({ }^{\circ} \mathrm{C}\right)$ & $\sigma(\mathrm{MPa})$ & $\tau(\mathrm{MPa})$ & $m(\mathrm{~g})$ \\
\hline 1 & 4 & 8 & 3 & 1 & 5 & 0.6 & 37.99 & 391.2 & 50.96 \\
2 & 1 & 4 & 5 & 3 & 8 & 0.95 & 145.7 & 211.9 & 42.7 \\
3 & 8 & 3 & 6 & 2 & 3 & 0.85 & 123.9 & 654.6 & 43.4 \\
4 & 3 & 7 & 7 & 6 & 2 & 1.05 & 157.1 & 520.1 & 60.592 \\
5 & 7 & 6 & 4 & 8 & 7 & 1 & 50.56 & 256.2 & 98.784 \\
6 & 2 & 2 & 2 & 7 & 4 & 1.5 & 165.9 & 477.1 & 36.624 \\
7 & 6 & 5 & 1 & 4 & 1 & 0.9 & 76.85 & 692 & 54.46 \\
8 & 5 & 1 & 8 & 5 & 6 & 1.1 & 289.3 & 561.1 & 40.166 \\
\hline
\end{tabular}

the middle will be removed, and the thickness should be increased, so the limit of the thickness $z$ of the solar panel is in the range $3.5-7 \mathrm{~mm}$. The size $d$ of the panel directly affects the thermal conductivity performance and structural strength of the solar panel, and the accuracy of the 3D aluminum alloy printing can be guaranteed at $0.1 \mathrm{~mm}$; therefore, the ranges of $d$ and $t$ are each determined as $0.15-0.5 \mathrm{~mm}$. The number of I-shaped beams will also directly affect the temperature difference and structural strength of the solar panel, as it can increase both the strength and weight of the panel; therefore, the number $n$ is determined to be in the range 50-120, and the range of $A$ is $0.2-1.6 \mathrm{~mm}$ according to the above parameters.

In general, the uniform test requires less test times and can greatly improve the optimization efficiency [43]. Therefore, this optimization method was also selected in this study. According to the range of the above five parameters, the parameter-level table of the uniform test is shown in Table 7. The parameters of these eight tests are input into the Sinda and Abaqus software, and the results of temperature difference, strength, and weight can be obtained, as shown in Table 8.
TABle 9: The analysis results of the $p$ value for $T, \sigma, \tau$, and $m$.

\begin{tabular}{lcccc}
\hline Factor & $p$ value for $T$ & $p$ value for $\sigma$ & $p$ value for $\tau$ & $p$ value for $m$ \\
\hline$n$ & 0.115 & 0.218 & 0.262 & 0.043 \\
$d$ & 0.061 & 0.079 & 0.095 & 0.027 \\
$A$ & 0.635 & 0.1 & 0.526 & 0.789 \\
$z$ & 0.0419 & 0.67 & 0.326 & 0.033 \\
$t$ & 0.285 & 0.407 & 0.025 & 0.091 \\
\hline
\end{tabular}

The result of the uniform test is to use the linear regression equation to describe the correlation between the parameters and the optimization targets. According to the simulation analysis and calculation results listed in Table 8, the regression model of the five parameters and the temperature difference, compressive strength, shear strength, and weight of the solar panel are established. The multiple $R$ values of the fitting results for temperature, difference performance, strength, and weight are $0.966,0.983,0.981$, and 0.987 , respectively, and it indicates that the linear regression model is reasonable. The regression equations are

$$
\begin{aligned}
T= & 1.17-3.964 \times 10^{-3} n-1.149 d-0.042 A \\
& +0.136 z-0.441 t \\
\sigma= & 290.734-1.106 n-419.343 d+92.592 A \\
& +5.887 z-134.628 t, \\
\tau= & 1024.577+1.493 n-582.067 d+37.354 A \\
& -24.264 z-1224.748 t, \\
m= & -91.835+0.446 n+112.773 d-1.473 A \\
& +9.972 z+60.708 t .
\end{aligned}
$$

In order to better determine the optimization results of the five parameters, we analyzed the impact of each parameter on the target value. In general, the smaller the $p$ value, the greater the impact on the target value, and the greater the impact of the change in the target value. In general, the $p$ value is less than 0.05 . The $p$ value analysis results of temperature difference, compressive strength, shear strength, and weight are shown in Table 9.

From Table 9, the order of influence of the five parameters on the target values $T, \sigma, \tau$, and $m$ can be obtained. The order of influence was $d>A>n>t>z, t>d>n>$ $z>A, z>d>n>t>A$, and $d>z>n>t>A$, respectively. The $n$ and $d$ values have the most significant effects on 


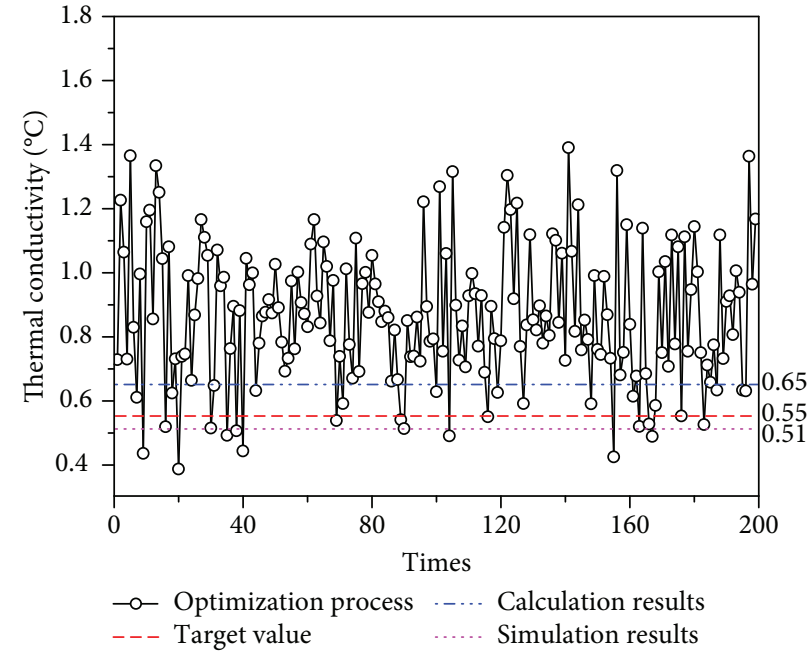

(a)

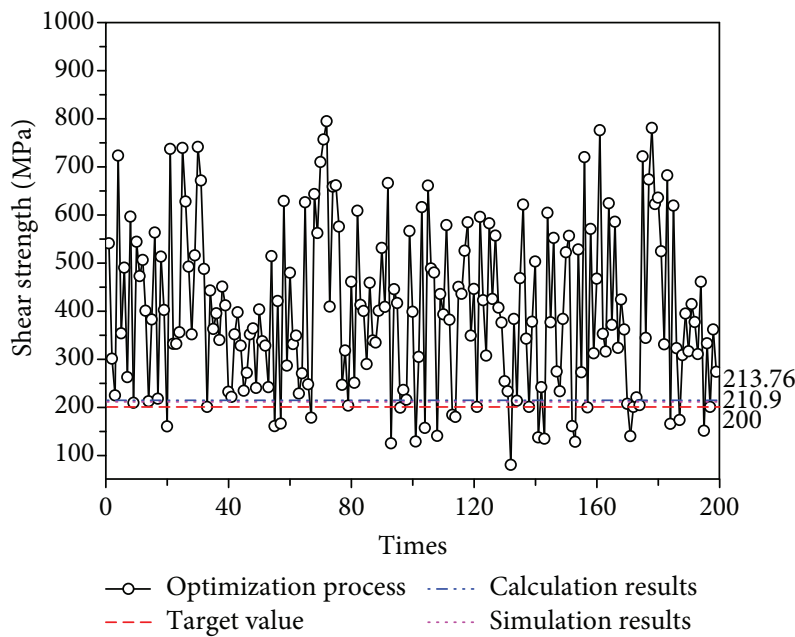

(c)

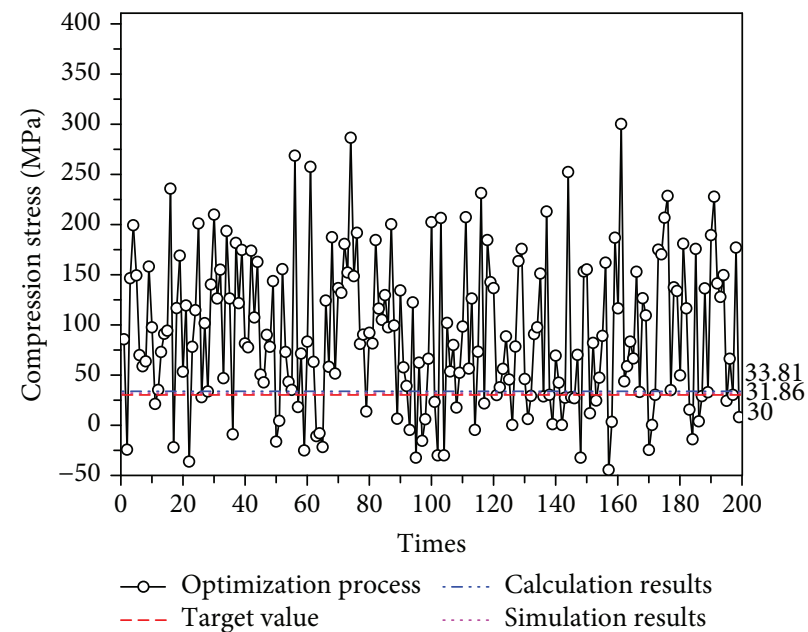

(b)

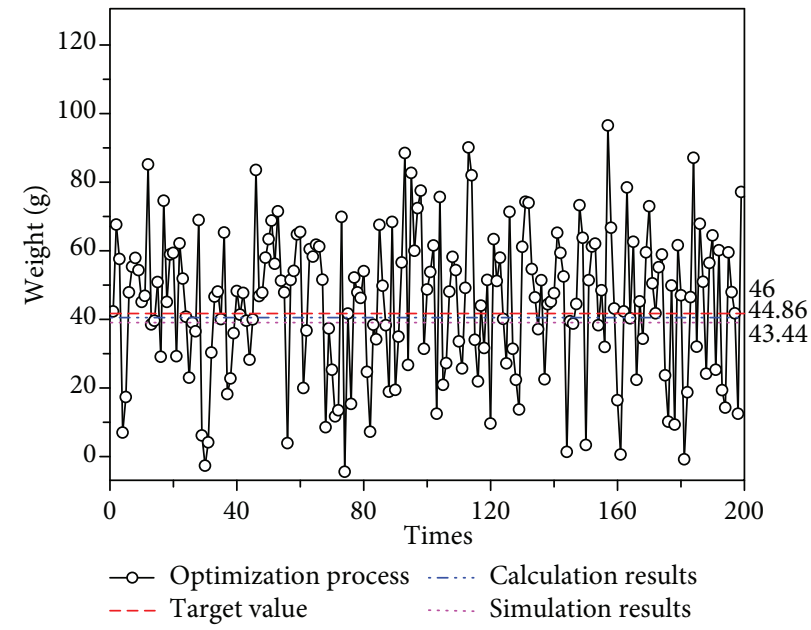

(d)

Figure 9: Optimization process, optimization results, and calculation results for (a) temperature difference, (b) compression strength, (c) shear strength, and (d) weight.

TABLe 10: Optimization and final structure parameters of the new type of solar panel.

\begin{tabular}{lcc}
\hline Factor & Optimization value & Final value \\
\hline$n$ & 55.136 & 55 \\
$d$ & $0.445 \mathrm{~mm}$ & $0.44 \mathrm{~mm}$ \\
$A$ & $0.315 \mathrm{~mm}$ & $0.32 \mathrm{~mm}$ \\
$z$ & $3.521 \mathrm{~mm}$ & $3.52 \mathrm{~mm}$ \\
$t$ & $0.469 \mathrm{~mm}$ & $0.47 \mathrm{~mm}$ \\
\hline
\end{tabular}

weight, and the effects on $\sigma, \tau$, and $T$ are not significant. Hence, the $n$ and $d$ values should be as small as possible. The value of $A$ has no significant effect on $\sigma, \tau, T$, and $m$; therefore, the value of $A$ is moderate. The $z$ value has significant effects on $m$ and $T$, while the $z$ value has a more significant effect on $m$ and has a small effect on $\sigma$ and $\tau$; therefore, the $z$ value should be selected to be as small as possible. The $t$ value has the most significant effect on
TABle 11: Performance comparison of the new type of solar panel between calculation and simulation.

\begin{tabular}{lcc}
\hline Performance & Calculation & Simulation \\
\hline$T$ (temperature difference) & 0.65 & 0.51 \\
$\sigma$ (compression stress) & 33.81 & 31.87 \\
$\tau$ (shear strength) & 213.76 & 210.9 \\
$m$ (weight) & 44.86 & 43.44 \\
\hline
\end{tabular}

$\tau$, and its effect on $\sigma, T$, and $m$ is not significant; therefore, the $t$ value should be large enough.

The optimization processes of $T, \sigma, \tau$, and $m$ are implemented with 1stOpt software. When the expression in Equation (4) is optimized to the target value 0 and the optimization ends, the values of each parameter can be obtained. The optimization process, calculation results, and optimization results are shown in Figure 9. According to an analysis of the five parameter value results, the final values of the five parameters are selected. They are listed in Table 10. 


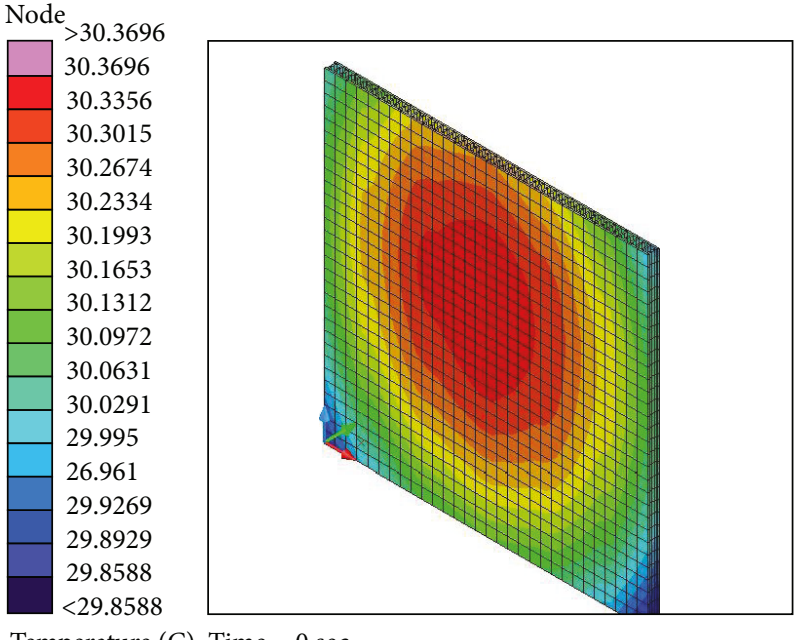

Temperature (C), Time $=0 \mathrm{sec}$

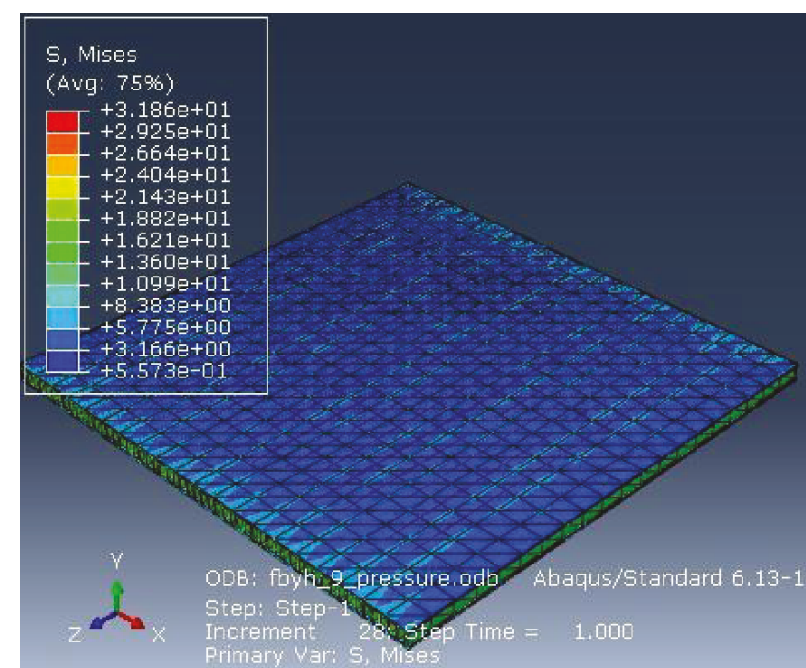

(b)

(a)

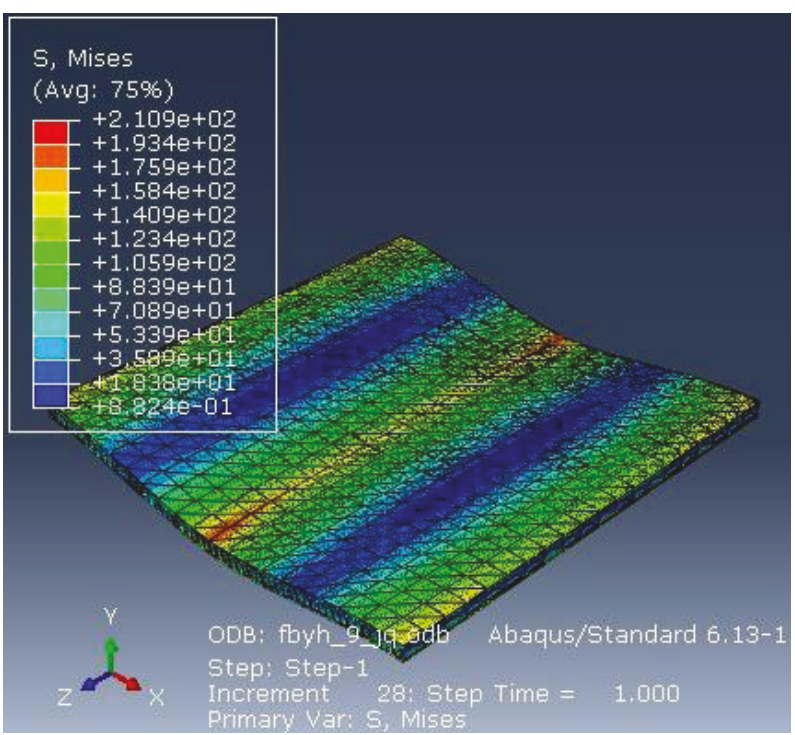

(c)

FIGURE 10: Performance analysis of the new type of solar panel after optimization (a) temperature difference, (b) compression strength, and (c) shear strength.

\section{Results Analysis and Test Verification}

The optimization results listed in Table 11 were used to establish a new type of solar panel model. The simulation results of temperature difference, compression strength, and shear strength are shown in Figure 10. By inputting the final values of the five parameters into Equations (5), (6), (7), and (8), the results of the regression model were obtained. The regression model calculation and simulation results of the temperature difference, compression strength, and shear strength of the new type of solar panel are shown in Table 11, and the weight of the model is $43.44 \mathrm{~g}$.

In order to evaluate the accuracy of the regression model, the deviation between the calculated values of the regression model and the simulation results and the deviation between the simulation results and the target values can be expressed as

$$
\begin{gathered}
e_{i}=\frac{\left|C_{i}-S_{i}\right|}{S_{i}} \times 100 \%, \\
\delta_{i}=\frac{\left|C_{i}-T_{i}\right|}{T_{i}} \times 100 \%,
\end{gathered}
$$

where $i$ represents the optimization targets $T, \sigma, \tau$, and $m$; $C$ is the calculation result, $S$ is the simulation result, and $T$ is the target value.

The analysis results of the relative deviations are listed in Table 12, and the results of the regression model and the simulation result for temperature difference, strength, and weight are $15 \%, 6.12 \%, 1.365 \%$, and $3.27 \%$, respectively. 
TABLE 12: The analysis results of the relative deviation $e_{i}$ and $\delta_{i}$.

\begin{tabular}{|c|c|c|c|c|c|}
\hline Performance & Target & Calculation results & Simulation results & $e_{i}$ & $\delta_{i}$ \\
\hline$T$ (temperature difference) & 0.55 & 0.65 & 0.51 & $27.45 \%$ & $18.18 \%$ \\
\hline$\sigma$ (compression stress) & 30 & 33.81 & 31.86 & $6.12 \%$ & $12.7 \%$ \\
\hline$\tau$ (shear strength) & 200 & 213.76 & 210.9 & $1.37 \%$ & $6.88 \%$ \\
\hline$m$ (weight) & 46 & 44.86 & 43.44 & $3.27 \%$ & $2.48 \%$ \\
\hline
\end{tabular}

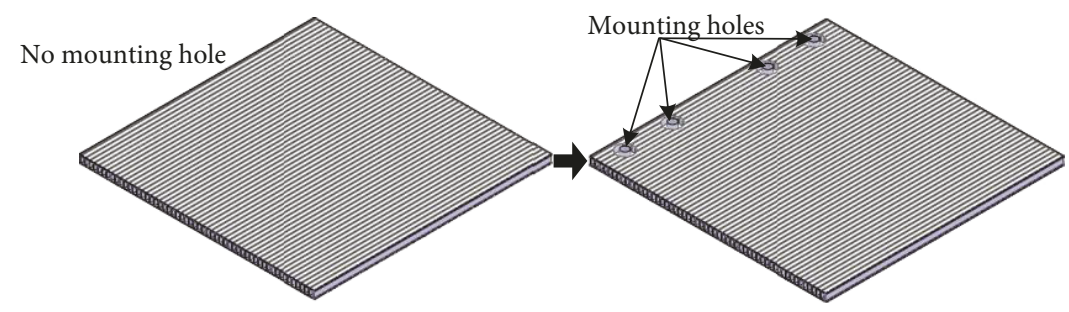

FIGURE 11: The new type of solar with mounting holes.

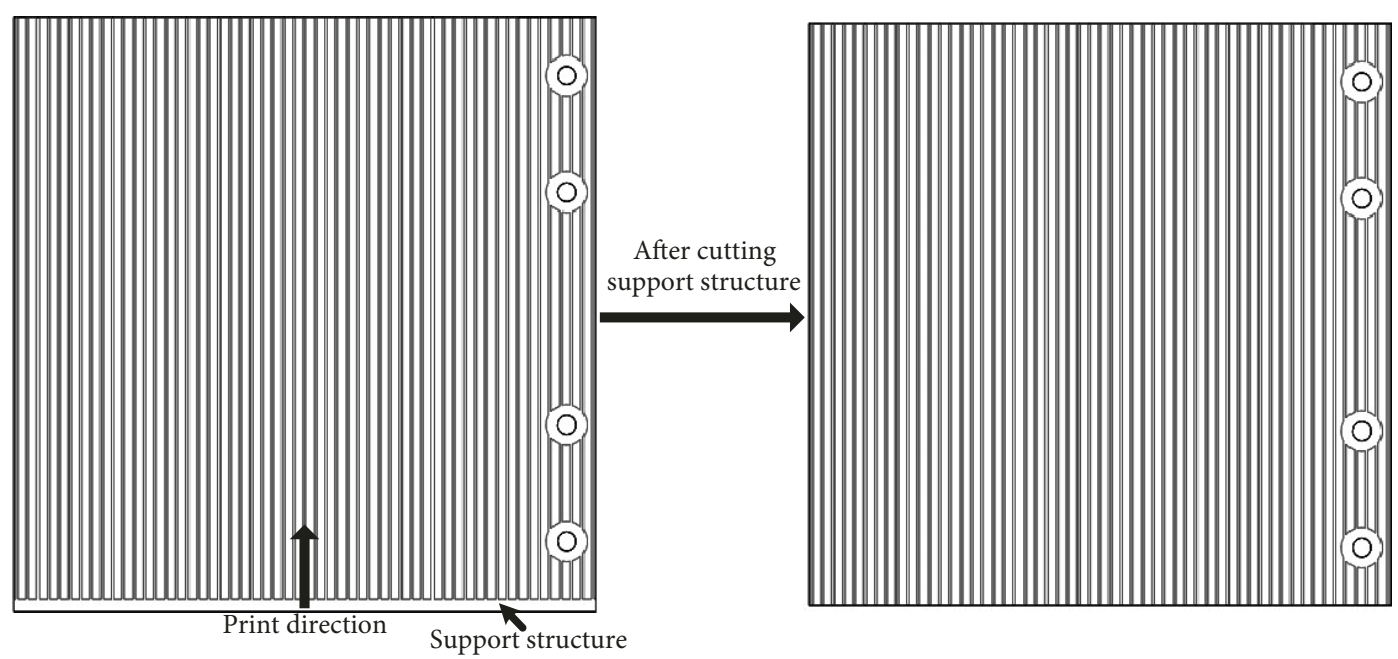

FIGURE 12: The print direction of the new type of solar panel and after cutting the support structure.

The deviations between the calculated results and the target value are $9.09 \%, 12.7 \%, 6.88 \%$, and $2.48 \%$, respectively. The results show that the regression model prediction can be used to predict the performance of the new type of solar panel.

Because of the structural features of the honeycomb aluminum plate, mounting holes cannot be drilled into it. The inserts must be added to the plate, and the mounting holes are drilled into the inserts, which are then fixed on the plate. The optimized new type of solar panel is not equipped with holes. In order to save the inserts, the mounting holes are directly printed onto the new type of solar panel, and the model structure of the $3 \mathrm{D}$ printing solar panel is shown in Figure 11. The print direction and support structure of the new type of solar panel are shown in Figure 12. Generally, the support structure should be printed on the structure in the printing process, which ensures the stability of the printing structure, and the support structure will be cut by wire cutting after printing. The postprocessing steps for the new type of solar panel are obtained from the literature [43]. The pictures of the new type of solar panel after processing are shown in Figure 13.
The performance of the new type of solar panel relative to the performance of the honeycomb aluminum plate can be expressed as

$$
\lambda_{i}=\frac{\left|C_{i}-H_{i}\right|}{H_{i}} \times 100 \%,
$$

where $H$ is the performance of the honeycomb aluminum plate.

The analysis results of the relative deviations $\lambda_{i}$ are shown in Table 13. It can be seen from Table 13 that the temperature difference, compressive strength, shear strength, and weight of the new type of solar panel are better than those of the honeycomb aluminum plate. The temperature difference is $91.62 \%$ higher than that of the honeycomb aluminum plate; that is to say, the temperature rise of the solar cell is not considerable when the new type of solar panel is exposed to direct sun radiation; thus, the efficiency of the solar panel will be higher than that of the aluminum honeycomb plate. For the same load, the compressive strength and 


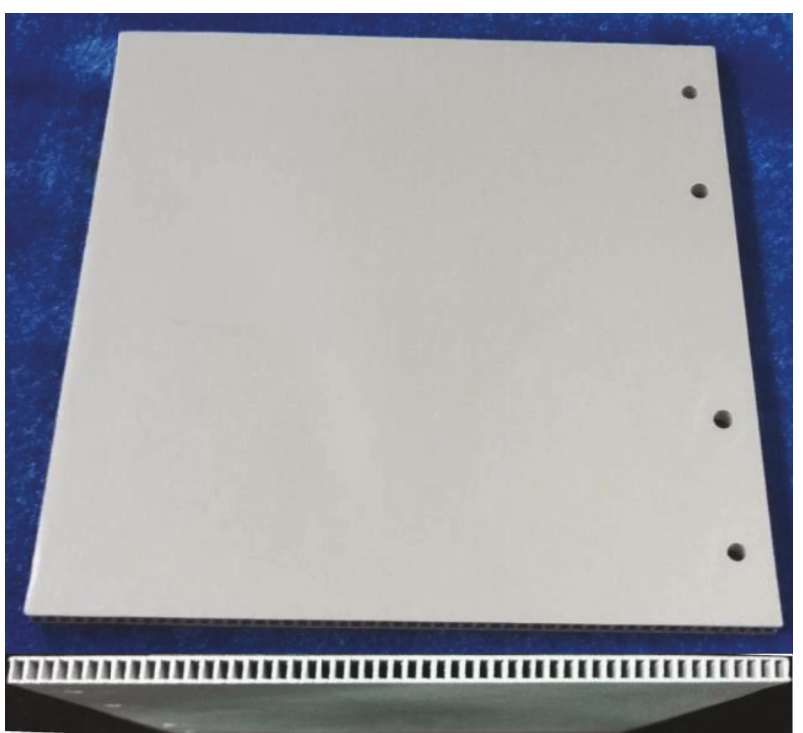

FIGURE 13: 3D metal printing of the new type of solar panel after processing.

TABLe 13: The analysis results of the relative deviation $\lambda_{i}$.

\begin{tabular}{lccc}
\hline Performance & $\begin{array}{c}\text { Honeycomb } \\
\text { aluminum plate }\end{array}$ & $\begin{array}{c}\text { New type of } \\
\text { solar panel }\end{array}$ & $\lambda_{i}$ \\
\hline $\begin{array}{l}T \text { (temperature } \\
\text { difference) }\end{array}$ & 7.76 & 0.65 & $91.62 \%$ \\
$\begin{array}{l}\sigma \text { (compression } \\
\text { stress) }\end{array}$ & 63.72 & 33.81 & $46.94 \%$ \\
$\tau$ (shear strength) & 260.4 & 213.76 & $17.91 \%$ \\
$m$ (weight) & 50 & 44.86 & $10.28 \%$ \\
\hline
\end{tabular}

shear strength increased by $46.94 \%$ and $17.91 \%$, respectively, indicating that the strength of the new type of solar panel structure was higher than that of the honeycomb aluminum plate. The weight was also $10.28 \%$ lower than that of the honeycomb aluminum, which is very significant for a large-scale panel satellite.

\section{Discussion}

As the honeycomb aluminum panels are all made of composite materials, the honeycomb aluminum core should be glued together with other components after the manufacturing of the honeycomb aluminum core. If the honeycomb aluminum plate is not made of composite material and aluminum alloy substrate is used instead, the connection between the upper and lower substrate and the aluminum honeycomb core should be welded. These two processes are rather tedious, with shortcomings that will affect the overall performance of the honeycomb aluminum plate. At the same time, the conventional honeycomb aluminum plate has a relatively long manufacturing cycle.

The installation of the honeycomb aluminum plate requires inserts, and the holes or threaded holes can be added on them. This kind of pre-embedding process is difficult to master, and it should be carried out during honeycomb aluminum manufacturing, which greatly limits the popularity of the honeycomb aluminum plate.

The temperature difference, pressure strength, shear strength, and weight of the honeycomb aluminum panels for space use are high. Therefore, the requirements for the composite and aluminum alloy materials used are high, and the process of making honeycomb aluminum plates is very long, which increases the cost of manufacturing honeycomb aluminum plates: in general, the cost of honeycomb aluminum plates is more than 150000 US dollars for $1 \mathrm{~m}^{2}$. The cycle of production of honeycomb aluminum plates is usually two months, and the period of developing new aluminum honeycomb panels is longer. If the insert's structure is added to the plates, the production and development cycle will increase.

The use of the new type of solar panel can effectively overcome the manufacturing limitations and reduce the costs associated with honeycomb aluminum plates. For the new type of solar panel structure, optimizations are made depending on the required performance according to specified needs. Furthermore, the installation holes are only created in the position that needs to be installed, and the structure can meet performance requirements after printing. In addition, the overall consistency of the structure is better. It only takes 1.5 days to print $100 \times 100 \times 3.52 \mathrm{~mm}^{3}$ of the new type of solar panel and only 40 days to print $1 \mathrm{~m}^{2}$, which can greatly shorten the development and manufacturing cycle. Moreover, 3D printing can use AA5024 aluminum alloy, which has a better performance than ordinary aluminum and a strength that is $100 \%$ higher than that of ordinary aluminum alloy. The cost of printing a $100 \times 100 \times 3.52 \mathrm{~mm}^{3}$ panel is 570 US dollars, while the cost of printing $1 \mathrm{~m}^{2}$ of the new type of solar panel is only 57000 US dollars, which can greatly reduce the cost of manufacturing. These advantages increase the engineering application value of the new type of solar panel.

\section{Conclusions}

(1) This paper presents a new method that replaces the conventional aluminum honeycomb panel with a new type of 3D metal printing structure for microsatellites that can address the manufacturing limitations and costs of a conventional aluminum honeycomb plate

(2) The multiobjective optimization method is used to optimize the temperature difference, compression strength, shear strength, and weight of the new type of solar panel structure. The relationships between the structural parameters of the panel and the optimal targets are established. Furthermore, the influence of the five factors on optimal targets are analyzed, and a group of better structural parameters are optimized

(3) The optimization results are verified via simulation and experiment. The results show that the deviations between the calculated results and the simulation 
result are $27.45 \%, 6.12 \%, 1.365 \%$, and $3.27 \%$, respectively, and the deviation between the calculated results and the target value are $18.18 \%, 12.7 \%$, $6.88 \%$, and $2.48 \%$, respectively. The optimized new type of solar panel structure is used for $3 \mathrm{D}$ printing, and the results show that compared with the conventional honeycomb aluminum plate, the temperature difference, compression strength, shear strength, and weight are increased by $91.62 \%, 46.94 \%$, $17.91 \%$, and $10.28 \%$, respectively. It is proved that this method can effectively improve temperature difference, compression strength, shear strength, and weight reduction of the solar panel. At the same time, this method can effectively shorten the development and manufacture cycle of the solar panel and also reduce the cost. It has high engineering application value

\section{Data Availability}

The data used to support the findings of this study are included within the article.

\section{Conflicts of Interest}

The authors declare that they have no conflicts of interest.

\section{Acknowledgments}

This research was funded by China National Funds for Distinguished Young Scientists (grant number 61525403).

\section{References}

[1] H. W. Brandhorst Jr and J. A. Rodiek, "Space solar array reliability: a study and recommendations," Acta Astronautica, vol. 63, no. 11-12, pp. 1233-1238, 2008.

[2] H. K. Kim and C. Y. Han, "Analytical and numerical approaches of a solar array thermal analysis in a low-earth orbit satellite," Advances in Space Research, vol. 46, no. 11, pp. 1427-1439, 2010.

[3] M. Yamashita and M. Gotoh, "Impact behavior of honeycomb structures with various cell specifications-numerical simulation and experiment," International Journal of Impact Engineering, vol. 32, no. 1-4, pp. 618-630, 2005.

[4] J. Feng, Y. Zhang, P. Wang, and H. Fan, "Oblique incidence performance of radar absorbing honeycombs," Composites Part B Engineering, vol. 99, pp. 465-471, 2016.

[5] H. Liu, Q. N. Yu, Z. C. Zhang, Z. G. Qu, and C. Z. Wang, "Two-equation method for heat transfer efficiency in metal honeycombs: an analytical solution," International Journal of Heat and Mass Transfer, vol. 97, pp. 201-210, 2016.

[6] C. J. Shen, G. Lu, and T. X. Yu, "Dynamic behavior of graded honeycombs-a finite element study," Composite Structures, vol. 98, no. 3, pp. 282-293, 2013.

[7] V. Caccese, J. R. Ferguson, and M. A. Edgecomb, "Optimal design of honeycomb material used to mitigate head impact," Composite Structures, vol. 100, pp. 404-412, 2013.

[8] J. R. Tanzman, "Material considerations in the STEREO solar array design," Acta Astronautica, vol. 63, no. 11-12, pp. 1239-1245, 2008.
[9] J. Li and S. Yan, "Thermally induced vibration of composite solar array with honeycomb panels in low earth orbit," Applied Thermal Engineering, vol. 71, no. 1, pp. 419-432, 2014.

[10] K. I. Song, J. Y. Choi, J. H. Kweon, J. H. Choi, and K. S. Kim, "An experimental study of the insert joint strength of composite sandwich structures," Composite Structures, vol. 86, no. 1-3, pp. 107-113, 2008.

[11] B. J. Kim and D. G. Lee, "Development of a satellite structure with the sandwich T-joint," Composite Structures, vol. 92, no. 2, pp. 460-468, 2010.

[12] A. Boudjemai, M. H. Bouanane, L. Merad, and A. M. Si Mohammed, "Small satellite structural optimisation using genetic algorithm approach," in Proceedings of the 3rd International Conference on Recent Advances in Space Technologies, pp. 398-406, Istanbul, Turkey, 2007.

[13] J. Zhang and M. F. Ashby, "Buckling of honeycombs under in-plane biaxial stresses," International Journal of Mechanical Sciences, vol. 34, no. 6, pp. 491-509, 1992.

[14] J. Zhang and M. F. Ashby, "The out-of-plane properties of honeycombs," International Journal of Mechanical Sciences, vol. 34, no. 6, pp. 475-489, 1992.

[15] W. Goldsmith and J. L. Sackman, "An experimental study of energy absorption in impact on sandwich plates," International Journal of Impact Engineering, vol. 12, no. 2, pp. 241-262, 1992.

[16] A. Boudjemai, M. Bekhti, M. H. Bouanane, A. M. Mohammed, G. Cooper, and G. Richardson, "Small satellite computer-aided design and manufacturing," Journal of Applied Polymer Science, vol. 581, no. 2, pp. 181-188, 2005.

[17] F. Hussain, M. Y. H. Othman, B. Yatim et al., "An improved design of photovoltaic/thermal solar collector," Solar Energy, vol. 122, pp. 885-891, 2015.

[18] E. A. Thornton and Y. A. Kim, "Thermally induced bending vibrations of a flexible rolled-up solar array," Journal of Spacecraft and Rockets, vol. 30, no. 4, pp. 438-448, 1993.

[19] P. W. Chung and E. A. Thornton, "Torsional buckling and vibrations of a flexible rolled-up solar array," in Proceedings of the 36th Structures, Structural Dynamics and Materials Conference, pp. 1654-1664, New Orleans, LA, USA, 1995.

[20] Y. Ding, M. D. Xue, L. J. Cheng, and H. Ning, "Fourier-finite element analysis of temperature fields in space structures," Journal of Tsinghua University(Science and Technology), vol. 42, no. 2, pp. 198-202, 2002.

[21] W. H. Yang, H. E. Cheng, and A. Cai, "Thermal analysis for folded solar array of spacecraft in orbit," Applied Thermal Engineering, vol. 24, no. 4, pp. 595-607, 2004.

[22] P. Li, H. E. Cheng, and W. B. Qin, "Numerical simulation of temperature field in solar arrays of spacecraft in low earth orbit," Numerical Heat Transfer, Part A: Applications, vol. 49, no. 8, pp. 803-820, 2006.

[23] J. Li, S. Yan, and R. Cai, “Thermal analysis of composite solar array subjected to space heat flux," Aerospace Science and Technology, vol. 27, no. 1, pp. 84-94, 2013.

[24] O. T. Thomsen, "Sandwich plates with 'through-the-thickness' and 'fully potted' inserts: evaluation of differences in structural performance," Composite Structures, vol. 40, no. 2, pp. 159174, 1997.

[25] S. Heimbs and M. Pein, "Failure behaviour of honeycomb sandwich corner joints and inserts," Composite Structures, vol. 89, no. 4, pp. 575-588, 2009. 
[26] B. Smith and B. Banerjee, "Reliability of inserts in sandwich composite panels," Composite Structures, vol. 94, no. 3, pp. 820-829, 2012.

[27] S. J. Huang, H. L. Lin, and H. W. Liu, "Electronic speckle pattern interferometry applied to the displacement measurement of sandwich plates with two 'fully potted' inserts," Composite Structures, vol. 79, no. 2, pp. 157-162, 2007.

[28] E. Bozhevolnaya and A. Lyckegaard, "Structurally graded core inserts in sandwich panels," Composite Structures, vol. 68, no. 1, pp. 23-29, 2005.

[29] P. Bunyawanichakul, B. Castanie, and J. J. Barrau, "Non-linear finite element analysis of inserts in composite sandwich structures," Composites Part B Engineering, vol. 39, no. 7-8, pp. 1077-1092, 2008.

[30] B. J. Kim and D. G. Lee, "Characteristics of joining inserts for composite sandwich panels," Composite Structures, vol. 86, no. 1-3, pp. 55-60, 2008.

[31] G. Bianchi, G. S. Aglietti, and G. Richardson, "Optimization of bolted joints connecting honeycomb panels," in In Proceedings of the 10th European Conference on Spacecraft Structures, Materials and Mechanical Testing, Berlin, Germany, 2007.

[32] P. Bunyawanichakul, B. Castanie, and J. . J. Barrau, "Experimental and numerical analysis of inserts in sandwich structures," Applied Composite Materials, vol. 12, no. 3-4, pp. 177-191, 2005.

[33] C. Burchardt, "Fatigue of sandwich structures with inserts," Composite Structures, vol. 40, no. 3-4, pp. 201-211, 1997.

[34] G. Demelio, K. Genovese, and C. Pappalettere, "An experimental investigation of static and fatigue behaviour of sandwich composite panels joined by fasteners," Composites Part B Engineering, vol. 32, no. 4, pp. 299-308, 2001.

[35] J. Cao and J. L. Grenestedt, "Design and testing of joints for composite sandwich/steel hybrid ship hulls," Composites Part A: Applied Science and Manufacturing, vol. 35, no. 9, pp. 1091-1105, 2004.

[36] H. Toftegaard and A. Lystrup, "Design and test of lightweight sandwich T-joint for naval ships," Composites Part A: Applied Science and Manufacturing, vol. 36, no. 8, pp. 1055-1065, 2005.

[37] F. Santoni, F. Piergentili, S. Donati, M. Perelli, A. Negri, and M. Marino, "An innovative deployable solar panel system for Cubesats," Acta Astronautica, vol. 95, no. 1, pp. 210-217, 2014.

[38] F. Santoni, F. Piergentili, G. P. Candini, M. Perelli, A. Negri, and M. Marino, "An orientable solar panel system for nanospacecraft,” Acta Astronautica, vol. 101, no. 1, pp. 120-128, 2014.

[39] J. Wang, C. Shi, N. Yang, H. Sun, Y. Liu, and B. Song, "Strength, stiffness, and panel peeling strength of carbon fiber-reinforced composite sandwich structures with aluminum honeycomb cores for vehicle body," Composite Structures, vol. 184, pp. 1189-1196, 2018.

[40] X. J. Zhang, S. Y. Tang, H. Y. Zhao et al., "Research status and key technologies of 3D printing," Journal of Materials Engineering, vol. 44, no. 2, pp. 122-128, 2016.

[41] Z. Zheng, L. Wang, and Y. B. Feng, "Research progress of 3D printing metal materials," Shanghai Nonferrous Metals, vol. 37, no. 1, pp. 57-60, 2016.

[42] L. B. Tan and X. H. Yu, "Application and prospect of 3D printing in metal forming," Journal of Netshape Forming Engineering, vol. 6, pp. 58-64, 2015.
[43] L. Teng and Z. Jin, "Structural performance optimization and verification of an improved thin-walled storage tank for a Pico-satellite," Applied Sciences, vol. 7, no. 11, 2017.

[44] J. Y. Che, L. D. He, and L. Yu, "Simulation and experimental study of the material properties of an aluminum honeycomb," Journal of Beijing University of Chemical Technology, vol. 36, no. 6, pp. 100-103, 2009.

[45] M. Salmi, J. Huuki, and I. F. Ituarte, "The ultrasonic burnishing of cobalt-chrome and stainless steel surface made by additive manufacturing," Progress in Additive Manufacturing, vol. 2, no. 1-2, pp. 31-41, 2017.

[46] A. Boudjemai, A. Mankour, H. Salem, R. Amri, R. Hocine, and B. Chouchaoui, "Inserts thermal coupling analysis in hexagonal honeycomb plates used for satellite structural design," Applied Thermal Engineering, vol. 67, no. 1-2, pp. 352-361, 2014. 


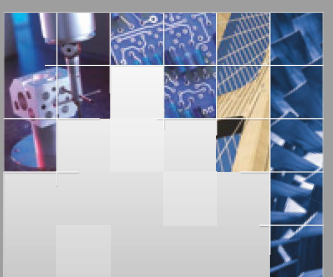

\section{Enfincering}
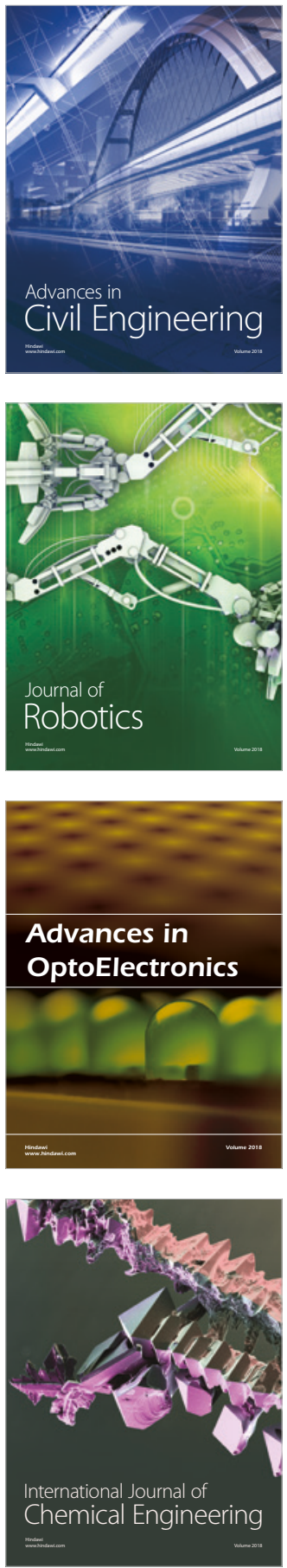

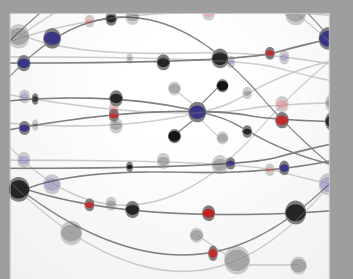

\section{Rotating \\ Machinery}

The Scientific World Journal

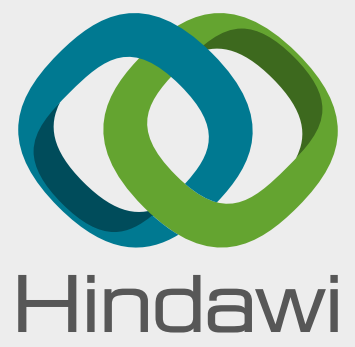

Submit your manuscripts at

www.hindawi.com
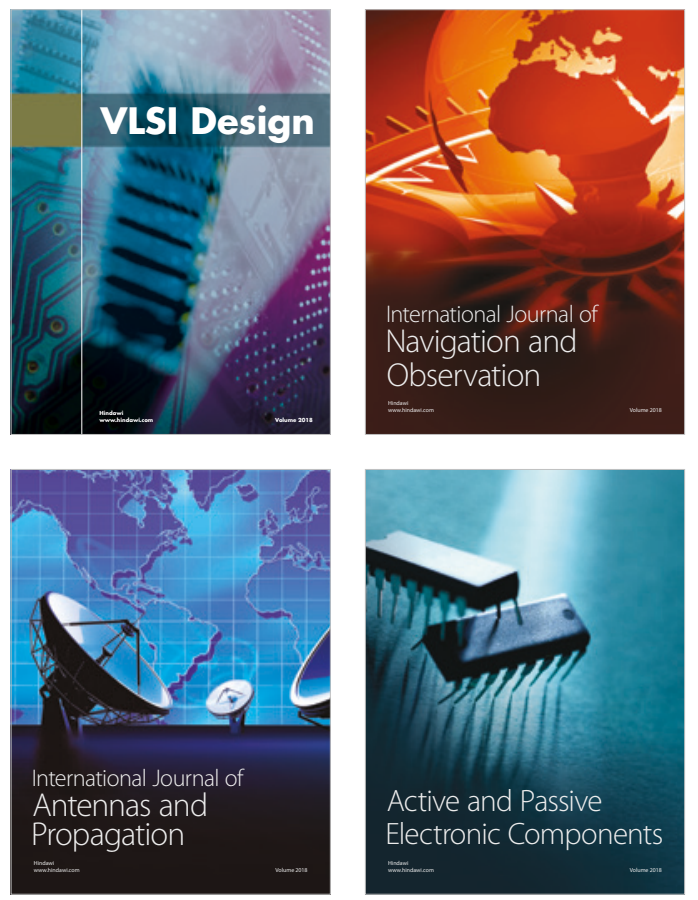
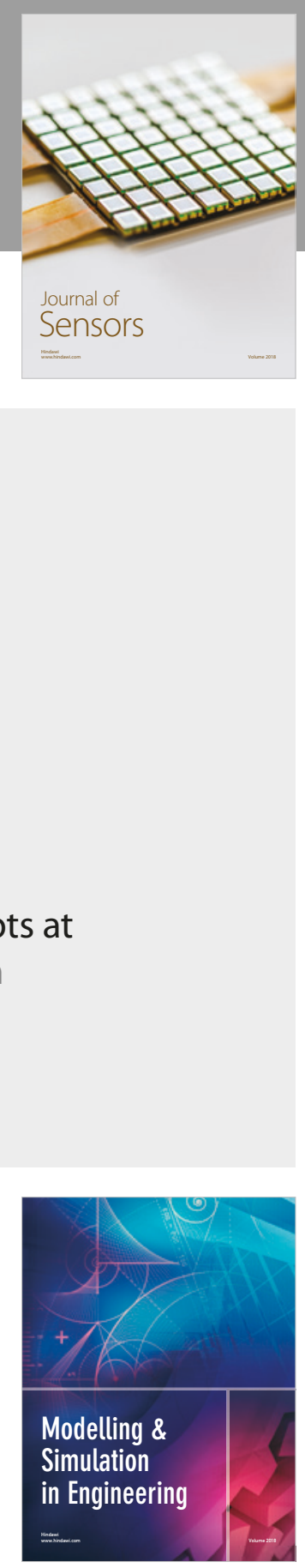

\section{Advances \\ Multimedia}
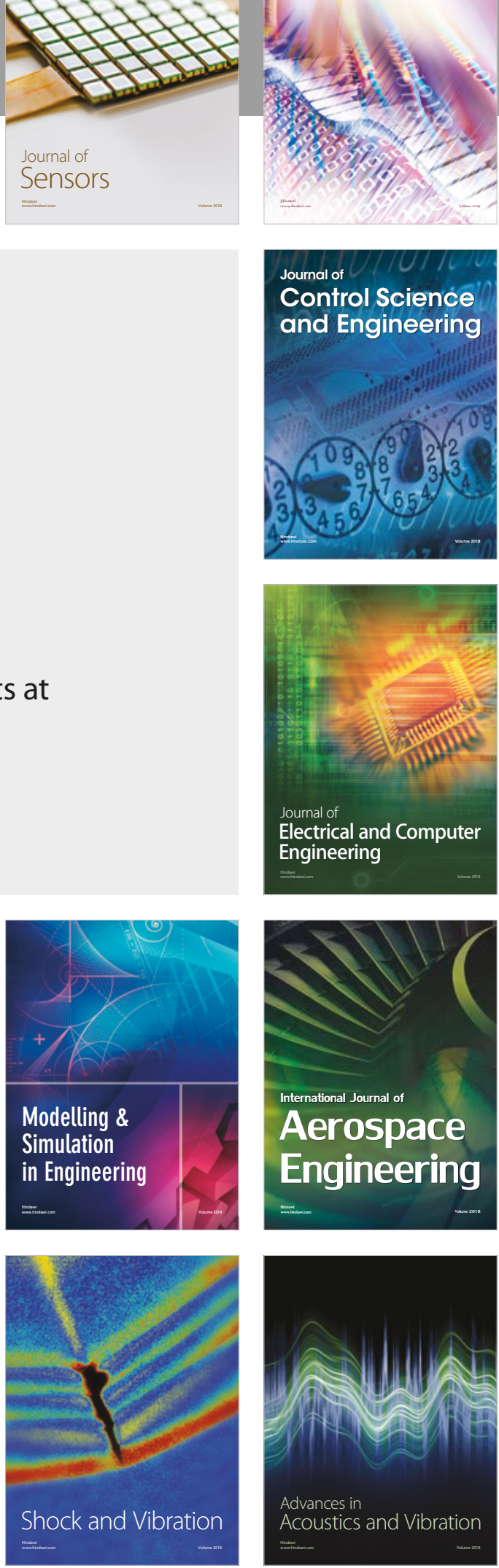